\title{
Research on the Use of Discourse Markers by English Teachers in EFL Classroom
}

\author{
Xiaojing Chen \\ Faculty of Foreign Languages \\ Huaiyin Institute of Technology \\ Huai'an, China 223001
}

\begin{abstract}
On the basis of reviewing the concept, nature and function of the discourse markers of domestic and foreign scholars, this paper adopts the form of corpus research to investigate the types, frequencies, dependent words and textual functions of the use of discourse markers by college English teachers in EFL classroom. Through investigation and analysis, it is found that the total frequency of the use of discourse markers by English teacher in EFL classroom is close to that of native speakers, but there are some problems: few types, high frequency, lack of diversity, excessive dependence on a discourse marker and combination of multiple discourse markers.
\end{abstract}

Keywords-discourse markers; corpus; pragmatic competence

\section{INTRODUCTION}

Discourse marker is ubiquitous in language use and can promote the understanding of discourse, which is an essential part of the fluency of discourse in natural communication. However, if the use of discourse markers is improper or inappropriate, it will hinder the smooth progress of communication. With the gestation, establishment and development of pragmatics research in second language acquisition, the study of discourse markers has gradually shifted from "syntax-semantics" to "pragmatic-cognition" and won a place in second language acquisition. Because of the different research methods and focuses, discourse markers are also given different terms, such as: sentence connectives, clue words, discourse particles, pragmatic Devices), and pragmatic markers. The diversity of terms also reflects the breadth of research methods: syntactic, semantic, and pragmatic. Chinese researchers also have some researches on discourse markers, including pragmatic study of discourse markers and corpus research on the use of discourse markers (He Ziran (2002), Ran Yongping (2000, 2002), Huang Dawang (2001), etc.). They have some discoveries through researches. From the perspective of meta pragmatic strategies, Li Xuejian believes that discourse marker as an important means of superficial textual cohesion is the description of meta pragmatic strategies and the externalization of meta pragmatic strategies $(2004,6)$. Yuan Wei and Feng Xiaoqing studied the contrast pragmatic mark, and proposed that the indirect mark has a historical development process from low subjective to subjective to interactive subjective according to Traugott's (interactive) subjective slope hypothesis $(2012,2)$. Guo Jianjing, He Anping and $\mathrm{Xu}$ Manfei used corpus to study the frequency of use, type and pragmatic function of Chinese college students' oral discourse markers. However, most of these studies are limited to English students. So, how do college English teachers use discourse markers in the EFL classroom environment? How is their ability to use discourse markers? Based on the shortcomings of this aspect, the author attempts to make some pioneering discussions on the types, frequencies, dependent words and their discourse functions of the use of discourse markers by college English teachers in EFL classroom through the investigation of teachers' classroom teaching expressions.

\section{DISCOURSE MARKERS}

\section{A. Definition and Characteristics of Discourse Markers}

Although there are many works about discourse markers, there is no unified conclusion about the definition and nature of discourse markers. Among them, the more influential ones are the "coherent school" led by Schiffin, Redeker, and Fraser and the "correlation school" led by Blakemore and Jucker et al.

Schiffrin (1987:31) proposed a discourse coherent model, which considers discourse markers to be non-independent component that connects discourse units in the discourse sequence. This component indicates the relationship between two adjacent discourse units and plays an important role in the coherence of dialogue. It is reflected in five aspects: exchange structure, behavior structure, concept structure, and participation mode and information situation. Fraser (1999) holds the similar point of view. He pays more attention to the cohesiveness of discourse markers in sentences and calls them pragmatic tokens, which distinguishes between discourse markers and pragmatic markers. He pointed out that only those words that connect two or more clauses can be called discourse markers, and the self-assessment markers and information source markers are excluded from the discourse markers. Unlike Schiffrin, Blakemore prefers to use a basic framework of relevance theory to interpret discourse markers from a cognitive-pragmatic perspective. Blakemore (1992) argues that the use of discourse markers is the necessary contextual assumption that is made to express contextual feature and contextual effects for communicators 
in verbal communication made to help communicators achieve this effect and adopt effective communicative language for communication.

Chinese scholar Ran Yongping (2000) believes that discourse markers convey neither the propositional meaning nor the semantic meaning. That is to say, they do not constitute the semantic content of discourse, but provide information marks for discourse comprehension to play the procedural meaning of guiding discourse understanding. Structurally, they are not limited to words, but also to phrases or structural combinations. They are part of the organization of discourse information. Their role is mainly to influence the construction and understanding of discourses as a whole, with dynamic pragmatic features (He Nai, Yan Yongping, 1999). Shaolin (2012) simplified the interpretation of discourse marker, which is defined as: discourse marker is an expression used to adjust and monitor verbal communication by the coding program information with independent intonation.

Although the domestic and foreign researchers have different views on the definitions and the characteristics of the discourse markers, they generally studied from the aspects of phonology, vocabulary, grammar, semantics and pragmatic features. Therefore, this paper defines it as: (1) not belonging to any part of speech; (2) independent tone units; (3) generally at the beginning of the segment; (4) independent in sentence; (5) grammatically arbitrary (6) no fixed semantic content; (7) reflexivity, regulates and monitors verbal communication; (8) mostly used in spoken language.

\section{B. The Function of Discourse Markers}

The research on the function of discourse markers is mainly semantic-pragmatic research and cognitive-pragmatic research. Scholars who focus on syntactic-pragmatic or semantic-pragmatic studies include Schourup, Erman, Schiffrin, and Fraser et al. They focus on the pragmatic functions of discourse markers according to the syntactic and semantic features of discourse markers to discuss the pragmatic function embodied in the discourse. They believe that the discourse markers plays a dynamic and important role in the coherence of discourse. Blakemore took the lead in studying the role of discourse markers from the perspective of cognitive-pragmatic teaching. The study of discourse markers is pushed from semantic-pragmatic research to cognitive-pragmatic research. Jucker and Ziv (1998: 4) summarize the four directions and main functions of discourse markers: (1) from the perspective of discourse, discourse marker is an important means of discourse organization, including all attached components that divide speech units in sequence; (2) from the perspective of modality, discourse marker is a means of pragmatic marker; (3) from the perspective of correspondence, discourse markers is a mark means suggesting and realizing interpersonal relationships between the two parties; 4) from the perspective of cognition, discourse markers is a mark means helping and guiding communicators to deal with discourse behavior (Wang Yang, 2005). Based on Brinton's research, Simone Mülle believes that discourse markers have several functions: (1) arousing discourse; (2) marking the boundaries between discourse; (3) predicting answers or reflections; (4) acting as a filter for discourse or delay skills; (5) helping the speaker to stand firm; (6) forming a good interaction between the speaker and the listener; (7) marking the anaphoric and back discourse (8) marking the foreground or background information. From the perspective of meta pragmatic strategies, Verschueren believes that discourse marker is a linguistic means indicating the speaker's metapragmatic consciousness, which is used to indicate the connection and coherence relationship between a discourse and other parts of the discourse; or it is an attitude or cognitive attribute that indicates the content of the proposition of the speaker's dialogue (Verschueren, 2000: 189). Ran Yongping believes that (2000): discourse markers can cognitively play a guiding or signpost function in conversational understanding partly or overall, help the hearers to recognize the various pragmatic relations of discourse, and thus constrain the understanding of discourse.

In summary, we find that although there are many researches on the discourse markers of Chinese and foreign students, there is still blank in the study of discourse markers of college English teachers in EFL classroom. Therefore, it is necessary to investigate the types, frequencies, dependent words and their textual functions of discourse markers.

\section{RESEARCH DESIGN}

In many years of teaching, the author realized that discourse marker is an important part of teacher-student communication. In teaching, teacher discourse accounts for a large proportion and plays a decisive role in teaching. It is necessary to study the discourse markers of teachers' classroom language in this special language context. This paper selects the teaching videos of 40 teachers who won the final of the "Foreign Education Community Cup" National College English Teaching Contest as research objects, then transfers them into text, and builds the corpus to make analysis from bottom to top by combining quantification and qualitative diagnosis with data as the support.

\section{A. Research Questions}

- What is the type and frequency of the use of discourse markers by college English teachers in the EFL classroom?

- What are the characteristics of their use of discourse markers?

\section{B. Research Objects}

This study selected 40 teachers who participated in the final of the "Foreign Education Community Cup" National College English Teaching Contest and won the award as the research objects. They are from 15 provinces or municipalities including Shandong, Xinjiang and Shanghai. The organizers of the competition randomly distribute students for the participating teachers. The teaching context is similar to the natural classroom. The textbook used is a new edition of the comprehensive course and audio-visual 
course published by Shanghai Foreign Language Education Press.

\section{Corpus}

This study uses a self-built corpus, which contains a total of 40 final courses of the contestants, and about 12 hours (15-20 minutes per lesson) of the transcriptional corpus, including the teacher's monologue, and the dialogue between the teacher and the student. Since the courses of the National English Teaching Contest are selected by the provincial competitions and reviewed by the final judges, the corpus can reflect the excellent college English classroom teaching discourse in recent years.

\section{Survey Method}

This study uses the wordsmith search tool to measure the frequency of use of teachers' discourse markers in corpus. The vocabulary search function is used to quantitatively and qualitatively analyze the type of use of teachers' discourse markers and the use of individual high-frequency discourse markers.

\section{E. Determining Search Terms and Language Examples}

Based on the words used in the study of Chinese college students' spoken English Small Words made by He Anping and $\mathrm{Xu}$ Manfei the author made some adjustment according to the actual use of teachers, and took the total of 20 words as search terms, taking the established language examples that identify small words as reference principle.

Word-based: ah, just, like, okay, oh, right, well, so, and.

Phrase-type: a bit, all right, I know, I mean, I see, I think, not really, or something, sort/kind of, you know, you see.

\section{RESULTS AND DISCUSSION}

\section{A. The Type and Frequency Analysis of the Use of Discourse Markers by English Teachers in EFL Classroom}

TABLE I. TYPE AND FREQUENCY DiSTRIBUTION OF WORD-BASED DisCOURSE MARKERS

\begin{tabular}{|c|c|c|c|c|c|c|c|c|c|c|c|}
\hline types & ah & just & like & okay & oh & right & well & so & and & total of frequency & total of types \\
\hline & 2 & 4 & 2 & 126 & 10 & 62 & 22 & 80 & 56 & 364 & 9 \\
\hline
\end{tabular}

TABLE II. Type AND FreQuency Distribution of Phrase-type Discourse Markers

\begin{tabular}{|c|c|c|c|c|c|c|c|c|c|c|c|c|}
\hline types & a bit & all right & $\begin{array}{c}\text { I } \\
\text { know }\end{array}$ & $\begin{array}{c}\text { I } \\
\text { mean }\end{array}$ & I see & $\begin{array}{c}\text { I } \\
\text { think }\end{array}$ & $\begin{array}{c}\text { not } \\
\text { really }\end{array}$ & $\begin{array}{c}\text { or } \\
\text { something }\end{array}$ & $\begin{array}{c}\text { kind of } \\
\text { knou } \\
\text { know }\end{array}$ & $\begin{array}{c}\text { you } \\
\text { see }\end{array}$ & $\begin{array}{c}\text { total of } \\
\text { frequenc } \\
\text { y }\end{array}$ & $\begin{array}{c}\text { total } \\
\text { of } \\
\text { types }\end{array}$ \\
\hline & 2 & 16 & 2 & 1 & 0 & 2 & 0 & 0 & 0 & 22 & 0 & 45 \\
\hline
\end{tabular}

"Table I" and "Table II" show the overall usage of wordbased and phrase-type discourse markers by English teachers in EFL classroom. From the perspective of the type and frequency of use, the frequency of use of discourse markers by English teachers in the EFL classroom is relatively high, totaling 409 words / 10,000 words. There are 9 kinds of word-based discourse markers, and the frequency of use is 364 words / 10,000 words; there are 6 kinds of phrase-style discourse markers, with the frequency of use 45 words / 10,000 words. The frequency and type of use of words greatly exceeds the use of phrases. The high-frequency word-based and phrase-type discourse markers are: okay, right, well, so, and, you know. Compared with the "Study on Chinese students' spoken English small words" of He Anping and $\mathrm{Xu}$ Manfei's, the frequency of the use of discourse markers by English teachers in EFL classroom is much higher than that of Chinese English students (248 words / 10,000 words), which is close to the frequency of use of discourse markers in British adults (410 words / 10,000 words). This shows that the frequency of English teachers' using discourse markers is not much different from that of native speakers.

The high-frequency words in this study are "okay", "right", "well", "so", and "and". Compare with the highfrequency words used by He Anping and Xu Manfei: okay, oh, just. and the high-frequency words in Guo Jianjing's research: oh, just, well, right, ok, high-frequency words of discourse markers used by Chinese teachers and students newly include "so", and "and" but exclude "oh". In the textual cohesive function, "so" draws forth the result and mark the topic shift, etc.; "and" has the function of constructing the discourse and continuing the discourse. "Oh" means that the previous round of topic content changed one's original cognition or indicated deviation from the current discourse. The author believes that the research results of different research subjects are different. In the EFL classroom, teachers are still in a dominant position. In the classroom, teachers frequently use "so", and "and" to lead to the results, build new content, and enter the next discourse. The use of "so" and "and" at high frequencies is similar to the survey conducted by Simone Miller. His research on three English textbooks published in Germany during the 1980s and 1990s and their corpus and found that "so" and "well" appeared more frequently, while "like" almost did not appear. He believes that this to some extent explains the acquisition condition of the pragmatic competence of nonnative English learners in using discourse markers. The author believes that in foreign language teaching, not only foreign language teachers should improve their own language skills, but the preparation of foreign language textbooks should also pay attention to the importance of discourse markers.

"Table II" shows the low frequency of the two-word discourse markers used by teachers in EFL classroom. In 
addition to "you know", "all right" shown in "Table II", most of the two-words discourse markers used by Chinese teachers are in the form of "and+X", such as: "and s", "and also", "and then" and "and now". "and $+X$ " is mostly used for text construction. Through the "and $+X "$ form, the teacher conducts textual macro-control and micro-information processing management to maintain the fluency of the discourse. This is a reflection of the teacher's meta-linguistic awareness strategy.

\section{B. Characteristics of the Use of Discourse Markers by College English Teachers in Classroom Teaching}

1) The types of the use of discourse markers is less while the frequency is high

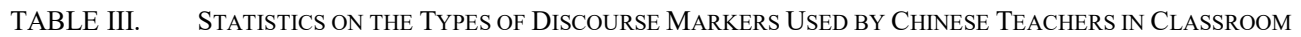

\begin{tabular}{|c|c|c|c|c|c|c|c|c|c|c|}
\hline & No.1 & No.2 & No.3 & No.4 & No.5 & No.6 & No.7 & No.8 & No.9 & No.10 \\
\hline & 7 & 7 & 12 & 9 & 6 & 10 & 8 & 10 & 9 & 7 \\
\hline & No.11 & No.12 & No.13 & No.14 & No.15 & No.16 & No.17 & No.18 & No.19 & No.20 \\
\hline & 7 & 6 & 8 & 8 & 9 & 11 & 10 & 12 & 8 & 9 \\
\hline & No.21 & No.22 & No.23 & No.24 & No.25 & No.26 & No.27 & No.28 & No.29 & No.30 \\
\hline & 9 & 7 & 8 & 8 & 6 & 7 & 9 & 9 & 10 & 10 \\
\hline & No.31 & No.32 & No.33 & No.34 & No.35 & No.36 & No.37 & No.38 & No.39 & No.40 \\
\hline & 11 & 10 & 9 & 7 & 9 & 9 & 7 & 8 & 9 & 10 \\
\hline
\end{tabular}

Although we provided 20 words including words and phrases as search terms in the study design, it can be seen from "Table III" that there are fewer types of discourse markers used by English teacher in EFL classroom. The average number of types is 8.625. Only 6 types are used less frequently, and the maximum number is only 12 . The statistics in "Table I" and "Table II" show that the overall frequency of the use of discourse markers by English teacher is not low. There is the condition of few types and high frequencies, which indicates that EFL classroom English teachers have a very concentrated selection of words when using discourse markers, and there are limitations in the types of use. This also partly explains He Heguo's research. In their research, the discourse markers used by college students in China is concentrated in a few word and single expression. Both teachers and students have the same problem. The author believes that the main reason is the lack of input of discourse markers. In China, foreign language teaching has not yet broken away from the pattern of word of mouth. The language input of foreign language learners mainly comes from the classroom, and the previous generation of teachers has a great influence on the next generation of students. If the teacher's own verbal ability is limited, it will inevitably affect the development of students' language ability. The statistical analysis of the frequency and type of the use of discourse markers by English teacher in this study also explains to some extent that there is the problem of low input quality lack of input type diversity in the input of discourse markers for Chinese English learners.

2) Over-reliance on a discourse marker: Another noteworthy feature is that almost every teacher has a discourse marker that he prefers/depends on. He/she will focus on using it whenever it is right or proper. The author randomly selected the classroom records of 10 teachers to find out that they have a special preference for "so" and "ok". The percentage of these terms in the total usage of discourse marker by teachers in classroom is shown in "Table IV":

TABLE IV. Proportion OF TEACHERS' PrefERENCE/DEPENDENCY WORDS

\begin{tabular}{|c|c|c|c|c|c|c|c|c|c|c|}
\hline & No.1 & No.2 & No.3 & No.4 & No.5 & No.6 & No.7 & No.8 & No.9 & No.10 \\
\hline $\begin{array}{c}\text { preference/dependent } \\
\text { words }\end{array}$ & so & ok & ok & ok & ok & so & so & ok & ok & ok \\
\hline percentage & $42 \%$ & $42 \%$ & $38 \%$ & $39 \%$ & $45 \%$ & $29 \%$ & $28 \%$ & $29 \%$ & $33 \%$ & $32 \%$ \\
\hline
\end{tabular}

From "Table IV", we can see that in one class only the use of "so" or "ok" is as high as $30 \%$ to nearly $45 \%$. This reflects that in the using process of the discourse markers by the English teacher in EFL classroom, they depend more on one or a few discourse markers. This also makes the types of discourse markers input for student concentrated and lack diversity, which greatly affects the acquisition of their discourse markers. This reflects the lack of knowledge and ability of English teachers' discourse markers in EFL classrooms. We further analyzed the use of "so" and "ok" and found that the use of discourse marker "so" by English teachers in EFL classroom is mainly limited to: drawing forth the results; acting as and discourse boundary indicator; expressing query or request as a verbal behavior marker; indicating an implied result. These functions are used to express the clarity of information and avoid ambiguity. The "ok" is mainly used for indicating the end of the previous turn and starting one's turn and give out the turn. Other functions are rarely involved. However, "so" as a discourse marker has nine functions and "ok" also has four functions. From the above specific analysis of so and ok, it can be seen that even for the high-frequency markers, English teachers can't not fully grasped and use reasonably.

3) Conjunction of several discourse markers: There is also the phenomenon that a number of discourse markers used together in the corpus. As shown in the following example:

Example 1: T: ...Gays and lesbians. Ok, well so, well, now you can guess the meaning. What's homonym? Because 
"nym" means name. So what's homonym? So homonym refers to the words they have the same pronunciation, the same spelling, but different meanings, right? Ok, well so this is so called 同音同行异议词, right? Ok, well. Let's have one example, so maybe youngsters you always use internet, right?

From the above example, we can see that teachers use several markers together. After we analyze the context, we find that it is not necessary to use the multi-word form to achieve the purpose of discourse coherence. The use of several discourse markers will inevitably lead to long and cumbersome language input, which will interfere with the acquisition of student discourse markers. After further analysis of the corpus is made, the author found that this is not a problem of one certain teacher, while nearly two-thirds of teachers have such problems. The author therefore interviewed some of the teachers at the school. When talking about the use of several words, they all said that they would use in such way, and they did not realize the problem. They think they didn't care, feel comfortable and smooth, or get used to it. The author believes that this is another signal that the use of discourse markers by English teachers in EFL classroom is lacking. Because they don't know how to use these discourse markers correctly, lack oral expression ability, and their code-switching ability is poor, in order to achieve the fluency of discourse, they use several discourse markers together.

\section{CONCLUSION}

Through investigation, it is found that in general, the use of discourse markers by English teachers in EFL classroom has the features of fewer types and high frequency of use. Besides, they have over-reliance on certain discourse markers in the classroom. In the teaching, through the repeated use of words and together use of words, they can achieve the purpose of continuing the discourse and promoting the smooth flow of words. To a certain extent, these reflect the problems of the pragmatic competence of English teachers in using discourse markers, which urgently need to be improved.

\section{REFERENCES}

[1] Blakemore, D. Understanding Utterances [M]. Oxford: Black-well. 1992.

[2] Schiffrin, D. Discourse Markers [M]. Cambridge: Cambridge University Press. 1987.

[3] Verschueren, Jef. Understanding Pragmatics [M]. Foreign Language Teaching and Research Press \& Edward Arnold Limited. 2000.

[4] Li Xuejian. Research on the Relationship between Discourse Markers and Meta-pragmatic Strategies[J]. Foreign Language Education. 2004(6): 4-8.

[5] Huang Dawang. A review of discourse markers[J]. Foreign Languages In Fujian, 2001(1): 5-11.

[6] He Ziran, Mo Aiping. Discourse Markers and bridging phenomenon [J]. Journal of Guangdong University of Foreign Studies, 2002(1):1-6.

[7] He Anping, Xu Manfei. Research on the use of Small Words in Speaking English by Chinese College students. [J] Foreign Language Teaching and Research, 2003 (6): 446-452.

[8] Guo Jianjing. Research on Discourse Marker Teaching. [J] Foreign language and Literature, 2012 (1): 128-132.
[9] Ran Yongping. Pragmatic Functions of Discourse Marker WELL[J] Journal of Foreign Languages, 2003(3): 58-63.

[10] Ran Yongping. A Review of the Pragmatics of Discourse Markers[J] Foreign Languages Research, 2000(4): 8-14.

[11] Simone Mülle, Huang Qin, Luo Xuanmin. A Review of Discourse Markers in English Conversation between Native Speakers and Nonnative Speakers[J]. Foreign Language Teaching and Research, 2008(9): 393-396.

[12] Wang Yang. Cognitive Pragmatic Interpretation of Discourse Markers [J]. Journal of Tianjin Foreign Studies University, 2005(3): 44-48.

[13] Yin Shulin. The Nature and Definition of Discourse Markers[J]. Foreign Language research, 2012(3): 91-95. 